\title{
Mesenteric Castleman's Disease: A Rare Cause of Mesenteric Masses: A Case Report and Literature Review
}

\author{
Abbas AR Mohamed ${ }^{1 *}$, Abdulsalam A Bin Hafiz ${ }^{2}$ \\ ${ }^{1}$ Consultant General and Laparoscopic Surgeon, Head of General Surgery Department, NGH -Madinah -KSA \\ ${ }^{2}$ Consultant General and Laparoscopic Surgeon, NGH -Madinah -KSA \\ * Corresponding author: Abbas AR Mohamed, Consultant General and Laparoscopic Surgeon, Head of General Surgery Department, NGH \\ -Madinah-KSA. \\ Received date: December 09, 2019; Accepted date: December 16, 2019; published date: January 16, 2020 \\ Citation: Abbas AR Mohamed, Abdulsalam Hafiz AB (2020) Mesenteric Castleman's Disease: A Rare Cause of Mesenteric Masses: A Case \\ Report and Literature Review. J Clinical Research and Reports, 1(1); DOI: 10.31579/JCRR/2020/005 \\ Copyright: (c) 2020 Abbas AR Mohamed. This is an open access article distributed under the Creative Commons Attribution License, which \\ permits unrestricted use, distribution, and reproduction in any medium, provided the original work is properly cited.
}

\begin{abstract}
:
Castleman's disease, also known as angiofollicular lymph node hyperplasia or giant lymph node hyperplasia, is a rare benign B-cell lymphoproliferative disorder of unknown etiology. We report a case of a 23-year old woman with mesenteric Castleman's disease of plasma cell variant presented as a palpable mass in the left iliac fossa.
\end{abstract}

Keywords: Mesenteric mass, Castleman's disease - Plasma cell variant.

\section{Introduction:}

Castleman's disease has been well described as a pathological entity in the scientific literature with only a few cases of mesenteric Castleman's disease reported. We report a rare case of mesenteric Castleman's disease of plasma cell variant in a young female, known case of autoimmune hemolytic anemia and antiphospholipid syndrome, who presented with a palpable mass in the left iliac fossa. The radiological investigations were suggestive of desmoids tumor or mesenteric carcinoid tumor. The mass was resected in total with part of the affiliated mesentery and associated lymph nodes and submitted to pathological analysis which established the diagnosis of Castleman's disease of plasma cell variant. We also review the literature for this rare disease involvement.

\section{Case Report:}

A 23-year old woman was referred to our surgical outpatient clinic because of recurrent left lower abdominal pain associated with constipation. She was a known case of autoimmune hemolytic anemia and antiphospholipid syndrome diagnosed at the age of 12 years. She had no history of thrombosis but was frequently admitted in the medical ward for treatment of anemia. On examination, she was pale, but not jaundiced or febrile, with normal vital signs. Her abdomen was not distended or tender, but relaxed. A palpable mass of about $5 \times 5 \mathrm{~cm}$ in the left iliac fossa was found. Her blood investigations showed hemoglobin of $9.6 \mathrm{~g} / \mathrm{dl}$, hematocrit: $31.5 \%$, MCV: 68.7, MCH: 20.9, MCHC 20.9 and ESR 74 $\mathrm{mm}$, associated with thrombocytosis and mild leukocytosis (platelet 559 $\mathrm{x} 10^{3} / \mathrm{mL}$ and $\left.\mathrm{WBCC} 12.7 \times 10^{9} / \mathrm{L}\right)$. Her coagulation screen showed slightly elevated prothrombin time (15.7- normal value 11-14.5 seconds) and INR (1.33\% -normal value $0.8-1.2 \%)$. Urea and electrolytes and liver function tests were within normal ranges. An abdominal CT showed a large mesenteric solid enhancing mass with a well-defined border containing multiple calcifications foci. The mass measured about 7 x 6.4 $x 5.5 \mathrm{~cm}$ and was located on the left side anterior to the lower pole of the left kidney. It showed no desmoplastic reaction and seem to be well separated from the adjacent bowel loops. multiple enlarged regional mesenteric lymph nodes were also noted, the largest one measured $18 \mathrm{x}$
$15 \mathrm{~mm}$. There was no organomegaly or associated ascites (figure 1-4). Abdominal radiographs suggested desmoids tumor or mesenteric carcinoid tumor. The chest $\mathrm{x}$-ray and CT radiographs did not show mediastinal involvement(figure 5-7).

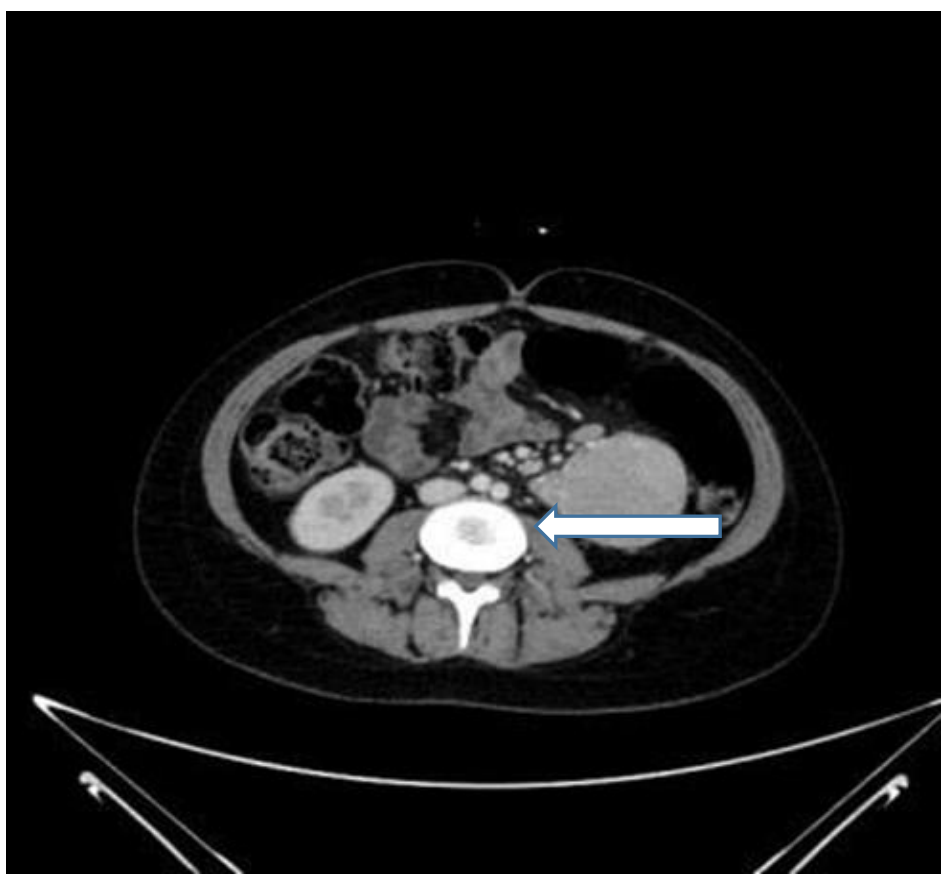

Figure 1: CT scan image (axial view) showing the mass (the arrow) with the associated mesenteric lymphadenopathy on the left side of the abdomen. 


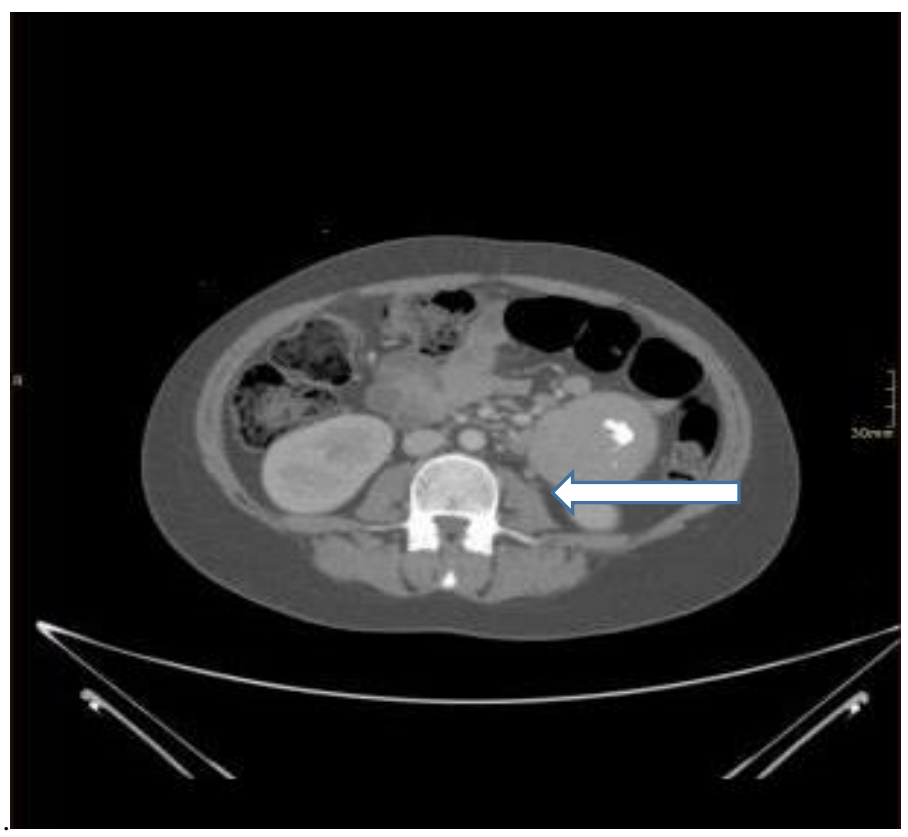

Figure 2: CT scan image (axial view) showing the calcification within the mass (the arrow) and the relation of the mass to the lower pole of the left kidney.

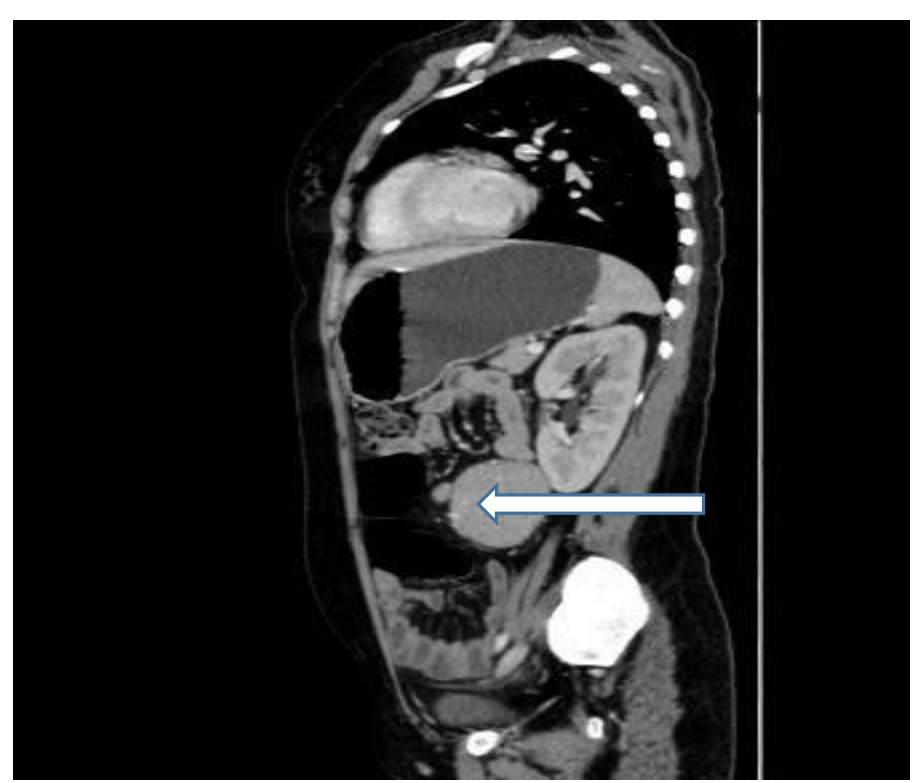

Figure 3: CT scan image (sagittal view) showing the same findings of figure 2(the arrow).

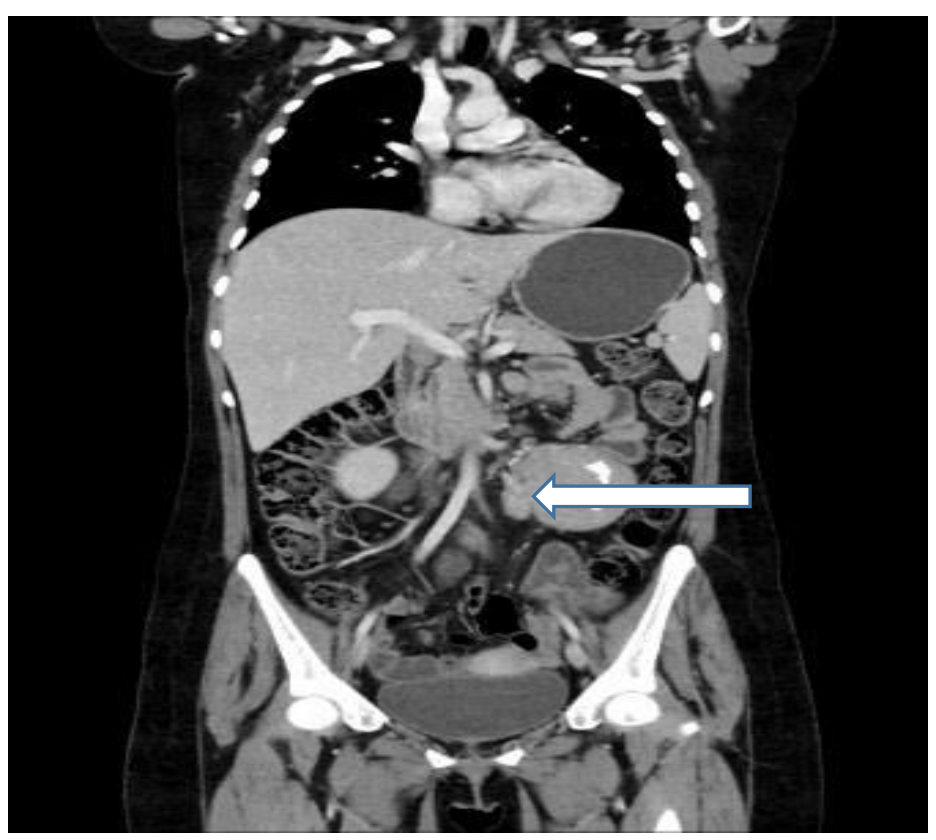

Figure 4: CT scan image (coronary view) showing the calcification within the mass (the arrow). and the relation of the mass to the great vessels.

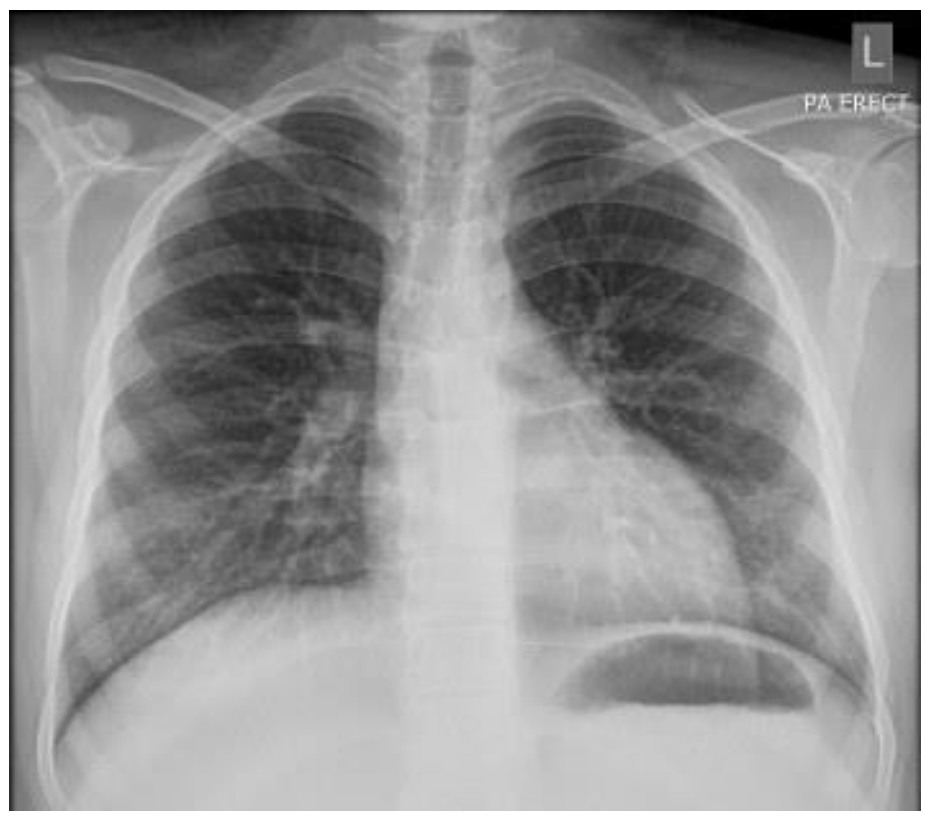

Figure 5: The chest $x$ ray showing no evidence of mediastinal mass. 


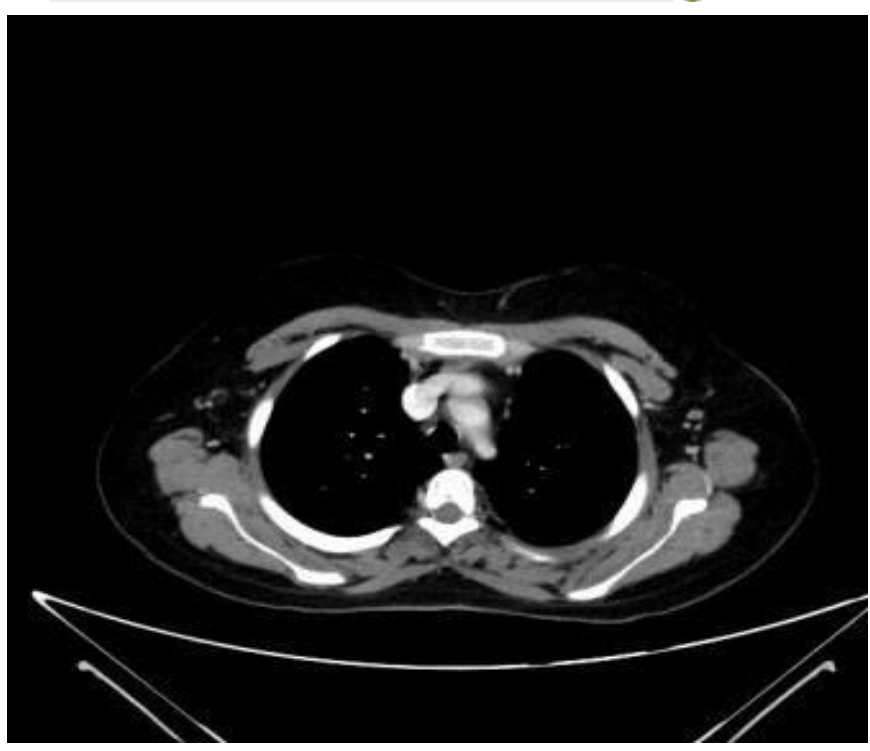

Figure 6: Images of the chest CT scan excluding mediastinal mass.

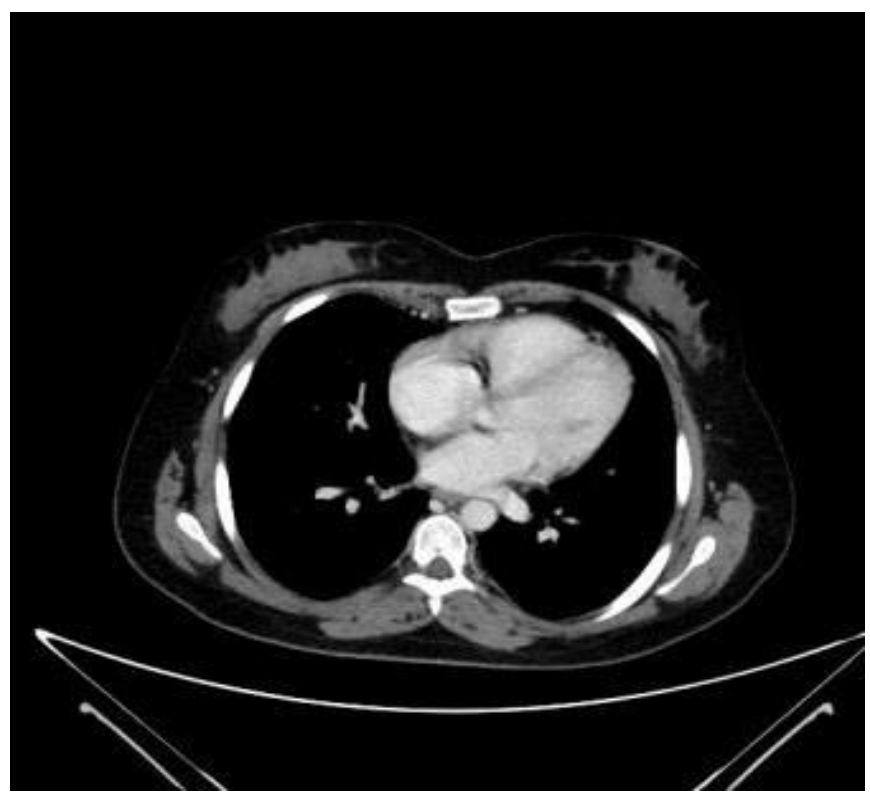

Figure 7: Images of the chest CT scan excluding mediastinal mass.

The decision was made to excise the mass and mesenteric lymph nodes. Laparoscopic Surgery was initially tried but was changed to open operation due to excessive bleeding. The mass was found not connected with either large or small bowels or left kidney and was dissected out in total with part of affiliated mesentery and associated lymph nodes and submitted to pathological analysis.

Gross examination revealed a round gray-tan soft tissue, 130 grams, $8.0 \mathrm{x}$ $6.0 \times 3.0 \mathrm{~cm}$. The tissue was serially cut. The cut surface showed was grayish, solid with areas of calcification. Microscopic examination of the mesenteric mass and lymph node showed lymphoid tissue with reactive follicular hyperplasia. The germinal centers were expanded and some areas showed hyaline vascular changes. The Para cortex showed sheets of mature plasma cells that are positive for CD138 with expression of both kappa and lambda light chains (kappa/lambda ratio 2:1). The lymphoid cells had a normal distribution of B and T cells (highlighted by CD20 and CD3 immuno-stains). Staining for HHV-8 and EBV-EBER were negative. The histopathology was consistent with the diagnosis of Castleman's disease, plasma cell variant.

Auctores Publishing - Volume 1(1)-005 www.auctoresonline.org Page - 3
The patient recovered well and was discharged on the $5^{\text {th }}$ postoperative day. She was further examined after 3 months with CT scans without contrast, whole body PE (7.16 mCi F18 FDG were injected, 70 minutes before image acquisition), which did not demonstrate hypermetabolic active foci ( figure $8 \& 9$ ).

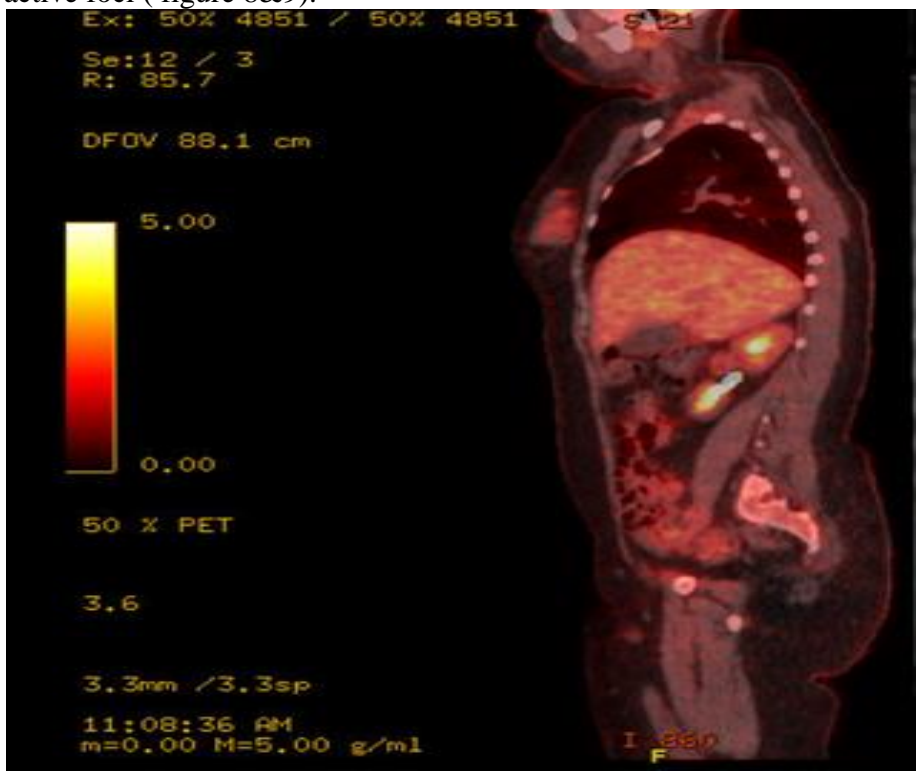

Figure 8: The F18 FDG PET demonstrating no hypermetabolic focus to suggest active disease.

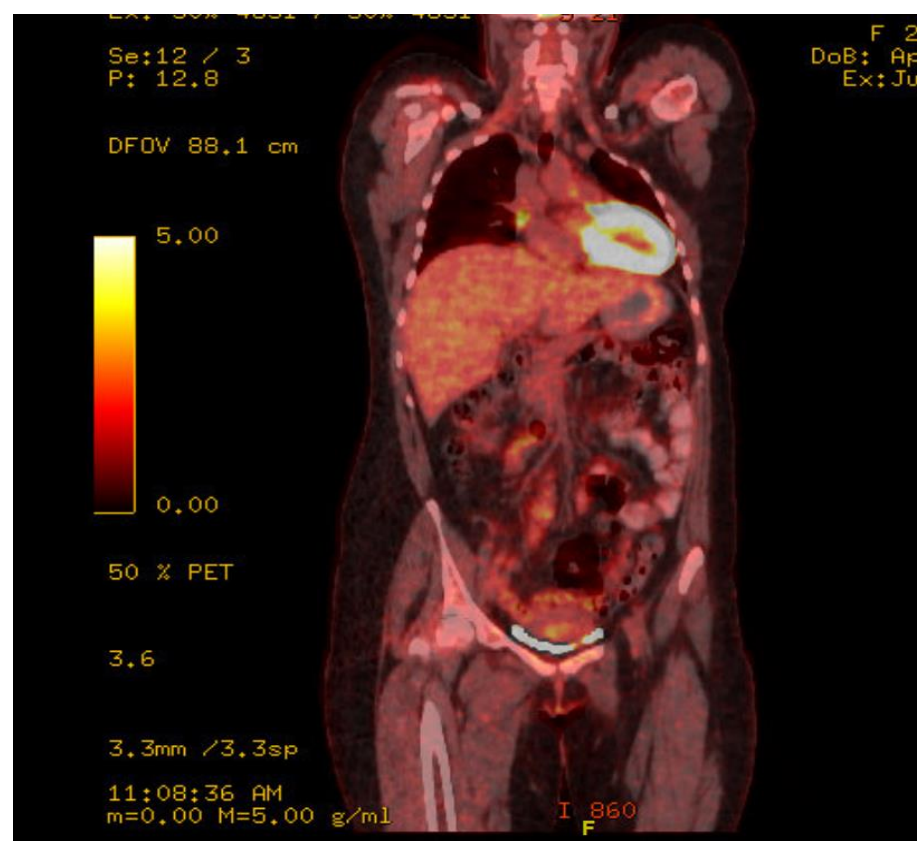

Figure 9: PET showing the same findings of figure 8.

\section{Discussions}

Castleman disease, also known as angiofollicular lymph node hyperplasia or giant lymph node hyperplasia, is an uncommon nonmalignant lymphoproliferative disorder was first described by Benjamin Castleman's in 1954 (1). It can occur anywhere within the body but only approximately 50 cases of mesenteric Castleman'sdisease have been reported within the literature (2).

Although the etiology of the disease is not yet fully understood, it is 
associated with chronic low-grade inflammations, immunodeficiency, and autoimmunity. It is suggested that the inflammatory mediators such as interleukin 6 (IL-6) play an important role in the pathogenesis of the disease. Studies in animals demonstrated that interleukin 6 stimulates Bcells and blood vessel proliferation through promoting the overexpression of the vascular endothelial growth factor and subsequent neoangiogenesis $(3,4)$.

Removal of mass causes an abrupt drop in IL-6 levels and resolution of symptoms (5) and the treatment with IL-6 receptor antibody relieves the clinical manifestations of the disease $(6,7)$. Experiments in mice documented that overexpression of IL- 6 produces a phenotype similar to the multicentric Castleman disease (8). These data suggest that IL-6 may play a crucial role in the pathogenesis of Castleman's disease.

Multicenteric form of the disease is associated with with immunodeficiency status and autoimmunity conditions including human immunodeficiency virus infection (HIV), human herpesvirus 8 infection (HHV-8), Kaposi's sarcoma, Hodgkin's lymphoma, non-Hodgkin's lymphoma, and POEMS syndrome (polyneuropathy, organomegaly, endocrinopathy, M protein and skin changes)(9-11).

Castleman's disease is classified into three histopathological patterns: a hyaline-vascular (HV) type, a plasma cell (PC) type and a mixed variant (12). More recently a new classification into 4 variants has been proposed: vascular-hyaline, plasma cell type, HHV-8-associated multicentric PC variant, and the idiopathic multicentric PC variant (iMCD) $(9,13)$

The hyaline-vascular is characterized histologically by lymphoid follicular proliferation at different levels of maturity, often forming a layered or 'onionskin' pattern surrounding a hyalinised prominent and reactive vessel at the centre of the follicle (14). It is the most common variant $(90 \%)$. It usually affects young people and is associated with the localized or unicentric form of the disease(15). It is usually silent without clinical symptoms but occasionally may present with pressure symptoms to adjacent structures.

The plasma cell variant was described by Flendrig and Schillings in 1969 (16) and further defined in 1972, by Keller et al(12), based on the discovery of mature sheets of plasma cells within the interfollicular tissues surrounding larger germinal centers associated with significantly less vascularity. Plasma cell Castleman's disease represents less than $10 \%$ of the cases and is usually characteristic of the generalized or multicentric form of the disease. the plasma cell type is characterized by fever, sweating, weight loss, anemia, an elevated erythrocytes sedimentation rate and hypergammaglobulinemia (17). It is commonly associated with human immunodeficiency virus infection (HIV), and human herpesvirus8 infection (HHV-8). Rarely, it may present as a unicentric variant with a good prognosis and responds to curative resection(18) as observed in our patient. Although Castleman's disease is not considered a neoplastic lesion, the multicentric variant is associated with an increased risk for the development of diffuse large B-cell lymphoma and Kaposi's sarcoma(1921).

The disease is also classified according to its presentation and biological behavior into unicentric and multicentric Castleman's disease. In the unicentric disease, one or more enlarged lymph nodes are present in a single region of lymph nodes while in the multicentric disease, enlarged lymph nodes are present in multiple regions of lymph nodes. The unicentric form Castleman's disease represents the most common form, and usually, the hyaline-vascular type tends to occur in the third and fourth decade of life, with a slight female predominance and with a median age of 35 years $(22,23)$. The widespread (multicentric) form of the disease is characterized by disseminated lymphadenopathy, almost always associated with systemic symptoms and dominated by the plasma cell type (24).

Castleman's disease can occur in any part of the body, but $70 \%$ of cases occur in the mediastinum (25). Extrathoracic sites have been reported in the neck, axilla, pelvis, and retroperitoneum $(12,26,27)$. Castleman's disease is very rarely located on the mesentery. Only 53 cases have been reported worldwide in the English literature till 2015(28).
Our case is one of those rare cases of localized unicentric plasma cell variant of mesenteric Castleman's disease, although it is associated with the general features of the multicentric disease. The case demonstrates well overlaps between the hyaline vascular and plasma cell variants in their biological behaviour, clinical presentation and disease association. Therefore, plasma cell variant warrants further screening of other regional lymph nodes with CT/PET whole-body scan.

Mesenteric Cattleman's disease needs to be differentiated from other lesions including desmoid tumor, lipoma, liposarcoma, leiomyoma, lymphoma, and gastrointestinal stromal tumors (31).

Diagnosis of mesenteric Castleman's disease is difficult to be established on radiological images as they are not specific for the disease. On ultrasound, the mesenteric Cattleman's mass shows a focal hypoechoic mass with mottled hyperechoic spots with increased vascularity on color Doppler. The mass on CT scan as a well-defined, homogeneous, single intraabdominal mass of soft-tissue attenuation with or without satellite nodules. The enhanced CT and angiography usually demonstrate the homogeneity and hypervascularity (32). Magnetic resonance imaging (MRI) of the lesion shows a low-intensity mass on T-1 weighted images and a higher signal intensity on T-2 weighted images $(32,33)$

Completely surgical excision of unicentric mesenteric tumors is the treatment of choice $(34,35)$. The multicentric form of the disease can be treated with a combination of immunotherapy (siltuximab or rituximab), chemotherapy, and corticosteroids, together with antiviral therapy in patients with HHV-8 or HIV.

\section{Conclusion:}

Mesenteric Castleman's disease is a rare entity with limited reports. Plasma cell variant is even rarer. The disease should be differentiated from other mesenteric masses, and should be suspected in young patients especially those with immune deficiency or autoimmune disease. Diagnosis of mesenteric Castleman's disease of plasma cell variant warrants thorough investigations to rule out multicenteric disease.

\section{Conflict of Interest: None declared}

\section{References}

1. Bhogal, Ricky H et al (2019) "Mesenteric Castleman's disease mimicking neuroendocrine tumour." International journal of surgery case reports vol. $63: 56-58$.

2. Castleman B, Towne VW (1954) Case records of the Massachusetts General Hospital: Case No. 40231. N Engl J Med. 250: 1001-1005.

3. Polizzotto MN, Uldrick TS, Wang V, Aleman K, Wyvill KM et al (2013) Human and viral interleukin-6 and other cytokines in Kaposi sarcoma herpesvirus-associated multicentric Castleman disease. Blood.122:4189-4198.

4. Chang KC, Wang YC, Hung LY, Huang WT, Tsou JH (2014) Monoclonality and cytogenetic abnormalities in hyaline vascular Castleman disease. Mod. Pathol.27:823-831.

5. Yoshizaki K, Matsuda T, Nishimoto N, Kuritani T, Taeho L et al (1989) Pathogenic significance of interleukin-6 (IL-6/BSF-2) in Castleman's disease. Blood. Sep;74(4):1360-1367

6. Nishimoto N, Kanakura Y, Aozasa K, Johkoh T, Nakamura M et al (2005) Humanized anti-interleukin-6 receptor antibody treatment of multicentric Castleman disease. Blood. Oct 15; 106(8):2627-2632.

7. Van Rhee F, Fayad L, Voorhees P, Furman R, Lonial S et al (2010) Siltuximab, a novel anti-interleukin-6 monoclonal antibody, for Castleman's disease. J Clin Oncol. Aug 10;28(23):3701-3708.

8. Brandt SJ, Bodine DM, Dunbar CE, Nienhuis AW (1990) Retroviral-mediated transfer of interleukin- 6 into hematopoietic 
cells of mice results in a syndrome resembling Castleman's disease. Curr Top Microbiol Immunol. 166:37-41.

9. Cronin DM, Warnke RA (2009) Castleman disease: an update on classification and the spectrum of associated lesions. Adv Anat Pathol. Jul; 16(4):236-46.

10. Chang Y, Cesarman E, Pessin MS (1994) Identification of herpesvirus-like DNA sequences in AIDS-associated Kaposi's sarcoma. Science.266:1865-1869.

11. Moore PS, Chang Y (1995) Detection of herpesvirus-like DNA sequences in Kaposi's sarcoma in patients with and without HIV infection. N Engl J Med. 332:1181-1185.

12. Keller AR, Hochholzer L, Castleman B (1972) Hyalinevascular and plasma-cell types of giant lymph node hyperplasia of the mediastinum and other locations. Cancer. Mar; 29(3):670-83.

13. Fajgenbaum DC, Uldrick TS, Bagg A et al (2017) International, evidence-based consensus diagnostic criteria for HHV-8negative/idiopathic multicentric Castleman disease. Blood. 29:1646-57.

14. Kasem AA, Al Thubaity T (2014) Castleman's disease. Egypt J Otolaryngol. 30:371.

15. Miguélez Vara C (2013) Enfermedad de Castleman mediastínica: presentación de un caso. Arch Bronconeumol. 49:455-6.

16. Flendrig JA (1969) Schillings PHM. Benign giant lymphoma: the clinical signs and symptoms. Folia Med Neerl.12:119-120.

17. Seco JL, Velasco F, Manuel JS, Serrano SR, Tomas L et al (1992) Retroperitoneal Castleman's disease. Surgery. 112:850 855.

18. Bonekamp D, Horton KM, Hruban RH, Fishman EK (2011) Castleman disease: the great mimic. Radiographics : a review publication of the Radiological Society of North America, Inc, $316,1793-807$.

19. Soumerai JD, Sohani AR, Abramson JS (2014) Diagnosis and management of Castleman disease. Cancer Control. 21:266278.

20. Kojima M, Nakamura N, Tsukamoto N (2008) Clinical implications of idiopathic multicentric Castleman disease among Japanese: a report of 28 cases. Int J Surg Pathol.16:3918.

21. Uldrick TS, Polizzotto MN, Yarchoan R (2012) Recent advances in Kaposi sarcoma herpesvirus- associated multicentric Castleman diseases. Curr Opin Oncol. 24:495-505
22. TJ Kim, JK Han, YH Kim, TK Kim, BI Choi (2001) “Castleman disease of the abdomen: imaging spectrum and clinicopathologic correlations," Journal of Computer Assisted Tomography, vol. 25, no. 2, pp. 207-214.

23. N. Talat, AP Belgaumkar, KM Schulte (2012) "Surgery in castlemans disease: a systematic review of 404 published cases," Annals of Surgery, vol. 255, no. 4, pp. 677-684.

24. Libson E, Fields S, Strauss S (1988) Widespread Castleman disease: CT and US findings. Radiology; 166:753.

25. Farruggia P, Trizzino A, Scibetta N, Cecchetto G, Guerrieri P et al (2011) Castleman's disease in childhood: report of three cases and review of the literature. Italian journal of pediatrics, 37, 50 .

26. Glazer M, Rao VM, Reiter D, McCue P (1995) Isolated Castleman disease of the neck: MR findings. AJNR Am J Neuroradiol. 16:669-671.

27. Meador TL, McLarney JK (2000) CT features of Castleman disease of the abdomen and pelvis. AJR Am J Roentgenol. 175:115-118.

28. Lv A, Hao C, Qian H, Leng J, Liu W (2015) Castleman disease of the mesentery as the great mimic: Incidental finding of one case and the literature review. Biosci Trends. Jun; 9(3):198-202.

29. Greco LG, Tedeschi M, Stasolla S, Gentile A, Gentile A (2010) Abdominal nodal localization of Castleman's disease: report of a case. Int J Surg. 8(8):620-2.

30. Ozsoy M, Ozsoy Z, Sahin S, Arıkan Y (2018) Rare Forms of Castleman Disease Mimicking Malignancy: Mesenteric and Pancreatic Involvement. Cureus. Mar 12; 10(3):e2310.

31. Silverman PM, Cooper C (1994) Mesenteric and omental lesions. In: Gore RM, Levin MS, Laufer I,eds. Texbook of gastrointestinal radiology. Philadephia: WB Saunders, 23672380

32. Malara F, Price D, Fabiny R (2000) Mesenteric Castleman's disease: Ultrasound, computed tomography and angiographic appearance. Australas Radiol. 44:109- 111.

33. Bartkowski DP, Ferrigni RG (1988) Castleman's disease: an unusual retroperitoneal mass. J Urol. 139:118-120.

34. Estephan FF, Elghetany MT, Berry M, Jones DV Jr (2005) Complete remission with anti-CD20 therapy for unicentric, non-HIV-associated, hyaline-vascular type, Castleman's disease. Cancer Invest. 23: 191.

35. Chen CH, Liu HC, Tung KY, Lee JJ, Liu CL et al (2007) Surgical outcome of superficial and deep Castleman disease. ANZ J Surg. May; 77(5):339-343. 